This item was submitted to Loughborough's Research Repository by the author.

Items in Figshare are protected by copyright, with all rights reserved, unless otherwise indicated.

\title{
No excess of mathematics anxiety in adolescents born very preterm
}

PLEASE CITE THE PUBLISHED VERSION

https://doi.org/10.1097/DBP.0000000000000884

PUBLISHER

Lippincott, Williams \& Wilkins

\section{VERSION}

AM (Accepted Manuscript)

\section{PUBLISHER STATEMENT}

This paper was accepted for publication in the journal Journal of Developmental and Behavioral Pediatrics and the definitive published version is available at https://doi.org/10.1097/DBP.0000000000000884.

\section{LICENCE}

CC BY-NC-ND 4.0

\section{REPOSITORY RECORD}

Trickett, Jayne, Camilla Gilmore, Lucy Cragg, Sarah Clayton, Neil Marlow, Victoria Simms, Rebecca Spong, and Samantha Johnson. 2020. "No Excess of Mathematics Anxiety in Adolescents Born Very Preterm". Loughborough University. https://hdl.handle.net/2134/12998792.v1. 
RUNNING HEAD: No mathematical anxiety following very preterm birth

No Excess of Mathematics Anxiety in Adolescents Born Very Preterm

This is the author's post-print of the article. The definitive version is published in the Journal of Developmental \& Behavioral Pediatrics

Jayne Trickett, $\mathrm{PhD}^{1,2}$, Camilla Gilmore, $\mathrm{PhD}^{1}$, Lucy Cragg, $\mathrm{PhD}^{3}$, Sarah Clayton, $\mathrm{PhD}^{2}$, Neil Marlow, FMedSci ${ }^{4}$, Victoria Simms, $\mathrm{PhD}^{5}$, Rebecca Spong, BSc${ }^{2}$, Samantha Johnson, $\mathrm{PhD}^{2 *}$

${ }^{1}$ Centre for Mathematical Cognition, Loughborough University, ${ }^{2}$ Department of Health Sciences, University of Leicester, Leicester, UK, ${ }^{3}$ School of Psychology, University of Nottingham, Nottingham, UK; ${ }^{4}$ Research Department of Academic Neonatology, Institute for Women's Health, University College London, London, UK; ${ }^{5}$ School of Psychology, Ulster University, Coleraine, UK.

*Corresponding author: Samantha Johnson

Department of Health Sciences, George

Davies Centre, University of Leicester,

Leicester, LE1 7RH ,United Kingdom

Sjj19@leicester.ac.uk 
RUNNING HEAD: No mathematical anxiety following very preterm birth

Conflicts of interest and sources of funding: This study was funded by an Action Medical Research (Ref: GN2311) project grant to SJ, CG, LC, VS and NM. The funder had no role in the study design, the collection, analysis, and interpretation of data, the writing of the report and the decision to submit the manuscript for publication. NM receives part funding from the Department of Health's NIHR Biomedical Research Centre's funding scheme at UCLH/UCL. The authors have no conflicts of interest to declare.

Acknowledgements: The authors wish to thank the adolescents who participated in the PRISM Studies, and their parents and teachers who supported study assessments and completed questionnaires. We also thank Dr Stephen Wardle for his support in recruiting adolescents born very preterm to the study. 


\section{Objective:}

To assess whether adolescents born very preterm (VP; <32 weeks' gestation) have an excess of mathematics anxiety compared with their classmates born at term.

\section{Methods:}

This cohort study included 127 adolescents born VP (51\% male, mean age 13.9 years, SD 0.7 ) and 95 term-born classmates (56\% male, mean age 13.7 years, SD 0.7) who completed the Wechsler Individual Achievement Test $2^{\text {nd }}$ UK Edition and the Mathematics Anxiety Scale-UK at age 11-15 years. Self-reported trait anxiety was assessed using a composite of three items from the Strengths and Difficulties Questionnaire.

\section{Results:}

Adolescents born VP had significantly poorer mathematics attainment than adolescents born at term (difference in means: $-0.64 \mathrm{SD} ; 95 \% \mathrm{CI}-0.95,-0.34$ ). However, there were no between-group differences in self-reported mathematics anxiety or trait anxiety. There were significant moderate associations between mathematics anxiety and mathematics attainment for adolescents born VP (rho: -.44) and at term (rho:-.52), after controlling for trait anxiety.

\section{Conclusion:}

Adolescents born VP do not have heightened mathematics anxiety compared with their termborn classmates, despite poorer attainment in mathematics. Improving domain-general cognitive skills and scaffolding learning in the classroom may be more promising avenues for intervention than attempting to reduce mathematics anxiety.

\section{Key terms:}

Preterm; outcome; anxiety; mathematics; cognition 
Children born very preterm (VP; <32 weeks' gestation) have poorer academic attainment and a higher risk for special educational needs than their term-born peers. ${ }^{1-3}$ The increased risk for poorer attainment is observed across all school subjects, but is especially evident in mathematics. ${ }^{3,4}$ In a meta-analysis of 17 studies, children born preterm $(<37$ weeks' gestation) had standardized arithmetic scores 0.71 SD lower than term-born controls, compared with deficits of $0.44 \mathrm{SD}$ and $0.52 \mathrm{SD}$ in reading and spelling, respectively. ${ }^{3}$ Previous studies have shown that domain-general cognitive skills, in particular poor working memory and visuospatial processing, as opposed to poor numerical representations, contribute to poorer mathematics attainment in children born VP. ${ }^{2}$ The relationship between domain-general cognitive skills and mathematics attainment is well-established in the general population. $^{5}$

An additional factor associated with mathematics attainment is mathematics anxiety. ${ }^{6}$ Mathematics anxiety is defined as 'a feeling of tension, apprehension, or fear that interferes with math performance' (Ashcraft, 2002, p181). ${ }^{7}$ Mathematics anxiety is moderately correlated with mathematics attainment $(\mathrm{r}=-0.27 \text { to }-0.30)^{8,9}$ and children with a mathematics learning difficulty (MLD) are at increased risk for high mathematics anxiety (scores $>90^{\text {th }}$ percentile) compared with children without $\operatorname{MLD}(22 \%$ vs. $10 \%) .{ }^{10}$ However, there is heterogeneity in the profiles of mathematics anxiety in children with MLD, as 78\% do not have high mathematics anxiety. ${ }^{10}$

Mathematics anxiety is associated with trait anxiety (i.e., a stable or enduring tendency to experience anxiety across many situations) in secondary school students in the general population (r .37 to $\mathrm{r} .41),{ }^{6}$ but it is also independently associated with mathematics attainment ( $\mathrm{r}-.22$ to $\mathrm{r}-.28)$ after controlling for trait anxiety. ${ }^{6} \mathrm{VP}$ birth is also a risk factor for anxiety symptoms and disorders in middle childhood. ${ }^{11}$ For example, in a recent metaanalysis of parent and teacher reports, adolescents born VP or with very low birthweight 
(VLBW; $\leq 1500 \mathrm{~g}$ ) were at increased risk of clinically significant anxiety problems compared with children born at term (OR 2.27; 95\% CI 1.15, 4.47). ${ }^{12}$ In adolescence, findings are mixed: some studies have reported significantly higher parent ratings of anxiety/depression for VLBW adolescents compared with term-born controls, or with normative data ${ }^{13,14}$, whilst others have not found higher parent-reported anxiety/depression symptoms among extremely low birthweight $(\leq 800 \mathrm{~g})$ adolescents. ${ }^{15}$ Likewise, self-reports of anxiety/depression symptoms in VLBW adolescents indicate no difference in depression/anxiety scores from controls. ${ }^{14}$ We are not aware of any studies that have explored mathematics anxiety in children born preterm.

Given the increased risk for anxiety after VP birth, ${ }^{12}$ the association between trait anxiety and mathematics anxiety in the general population, ${ }^{6}$ and the lower attainment in mathematics in VP adolescents, ${ }^{2}$ it was hypothesized that adolescents born VP will have higher levels of mathematics anxiety than their classmates born at term. It was also hypothesized that higher mathematics anxiety will be associated with poorer attainment in mathematics in both adolescents born VP and at term, after adjusting for trait anxiety.

\section{METHODS}

\section{Participants}

Participants comprised adolescents in the Premature Infants' Skills in Mathematics (PRISM) cohort. Previously, 117 children born very preterm (VP <32 weeks' gestation) and admitted to neonatal care in two UK centres were recruited to the PRISM study at age 8-10 years, of which 115 were assessed. Recruited children were representative of the total population of VP births ( $\mathrm{n}=266)$ in terms of gestational age, birthweight, sex and deprivation. ${ }^{2}$ A control group of 77 children born at term were recruited from age- and sex- matched classmates of the VP children. Detailed information about the cohort has been published previously. ${ }^{2}$ 
For the present study, these children were invited to participate in a follow-up assessment in adolescence. Of the original cohort, the parents of 87 (76\%) VP adolescents provided consent for their participation, of which 83 were assessed (Figure 1), and the parents of $51(67 \%)$ term-born controls provided consent. For VP adolescents for whom the parent of the original control did not provide consent, for whom there was no original control, or for whom the control had moved to a different school, a new/additional control was selected using the same procedure as in the original study. ${ }^{2}$ Thirty-one new controls were recruited in this way, resulting in a total of 82 controls, of which 78 were assessed (Figure 1).

For the original cohort, there was no significant difference between VP children who did and did not participate in the present study in gestational age $(\mathrm{p}=.580)$, birthweight $(\mathrm{p}=.369)$, nonverbal IQ $(\mathrm{p}=.082)$, or sex $(\mathrm{p}=1.00)$. However, VP children who were re-assessed had lower rates of deprivation $(37 \%)$ than those who did not participate $(62 \% ; \mathrm{p}=.042)$. For controls, there was no significant difference between children who did and did not participate in the present study in deprivation $(\mathrm{p}=.157)$ and sex $(\mathrm{p}=.636)$. However, children who were reassessed had higher non-verbal IQ $(\mathrm{M}=109.90, \mathrm{SD}=14.70)$ than those who were not $(\mathrm{M}=98.36, \mathrm{SD}=20.44 ; \mathrm{p}=.012)$.

To increase power for cross-sectional analyses, an additional 48 adolescents born $<32$ weeks' gestation were recruited from admissions to neonatal care in a third UK centre (Nottingham University Hospitals NHS Trust). Of 165 births, 135 were invited to participate, of which the parents of $48(36 \%)$ provided consent (Figure 1). Of these, two adolescents attending special schools were excluded and assessments could not be scheduled for a further two, leaving a total of 44 additional VP adolescents. Compared with the remaining VP population $(\mathrm{N}=121)$, there were no significant differences in gestational age $(\mathrm{p}=.271)$, birthweight $(\mathrm{p}=.457)$, deprivation $(\mathrm{p}=.576)$ or $\operatorname{sex}(\mathrm{p}=.981)$. An additional 18 classmates born at term and matched 
on age and sex to one of these VP adolescents were recruited. Of these, one was excluded because they had been living abroad leaving 17 additional controls.

In total, the assessed cohort comprised $127 \mathrm{VP}$ adolescents and 95 controls aged 11.82 to 15.17 years. Data were collected between January 2016 and January 2017.

\section{INSERT FIGURE 1 HERE}

\section{Procedure}

Informed parental consent and assent was obtained for all adolescents. Participants were assessed in school $(68 \%)$ or at home $(32 \%)$ by one of two psychologists who were blind to group membership.

\section{Measures}

Mathematics Attainment: The Wechsler Individual Achievement Test $2^{\text {nd }}$ UK Edition (WIAT-II $\left.{ }^{\mathrm{UK}},{ }^{16}\right)$ was used to assess attainment in mathematics. This examiner administered test yields an age-standardised mathematics composite score (mean 100, SD 15). Higher scores indicate better attainment.

Mathematics Anxiety: Adolescents completed the Mathematics Anxiety Scale-UK (MAS-UK, $\left.{ }^{17}\right)$. This questionnaire was developed using an undergraduate population in the United Kingdom. It comprises 23 items on a 5-point Likert scale (see Table S1) with responses ranging from 1 (Not at all) to 5 (Very much) from which a total score was computed (range 23 to 115). Three factors: mathematics evaluation anxiety, everyday/social mathematics anxiety and mathematics observation anxiety describe the content of the scale. The MAS-UK demonstrates good construct validity. In the validation study there was no correlation between a measure of general trait anxiety and mathematical performance, However, mathematical anxiety as measured by the MAS-UK total score was significantly negatively correlated with performance in mathematics. ${ }^{17}$ Internal consistency for the total 
score was excellent (Cronbach's alpha: VP 0.94; Controls 0.93). For seven participants with one item missing, data for the missing item was imputed from the average of 22 completed items. Higher scores indicate higher mathematics anxiety.

Trait Anxiety: Trait anxiety was assessed using the self-report version of the Strengths and Difficulties Questionnaire (SDQ,$\left.{ }^{18}\right)$ from which a total score for three items assessing anxiety (Items 8, 16 and 24) was computed. Higher scores indicate higher levels of anxiety. Items were scored on a three-point Likert scale ("Not True"=0, "Somewhat True"=1, "Certainly True"=2) so anxiety scores ranged from 0 to 6 . Cronbach's alpha for the selfreport trait anxiety score was 0.79 for the VP group and 0.70 for the control group. Parent-reported anxiety was calculated using scores on the same items from the parent report version of the SDQ. Cronbach's alpha for the parent-reported anxiety score was 0.71 for the VP group and 0.72 for the control group. The SDQ has a strong five factor structure, whereby items 8,16 and 24 load solely onto one factor. ${ }^{18}$ The SDQ is widely used in research and clinical practice and has excellent psychometric properties for identifying children with behavioural and emotional difficulties in both clinical and community populations.

Socioeconomic status: As an indicator of socio-economic status, the postal code of the parents' residence at the time of assessment was used to derive an Index of Multiple Deprivation (IMD) score. ${ }^{19}$ The IMD is a measure of relative deprivation comparing each neighbourhood to all others in England. The IMD is based on postcode of residence for lower-layer super output areas which cover an average of 1,500 residents. It is a composite indicator covering seven domains of deprivation (income, employment, education, health, crime, barriers to housing and services and living environment). ${ }^{19}$ Higher scores indicate higher levels of deprivation. Using IMD scores, participants were classified in one of three levels of deprivation using national statistics (least, middle or most deprived area of the UK). 
Non-verbal IQ: Non-verbal IQ was assessed using the Raven's Standard Progressive Matrices from which an age-standardized score was derived (mean: 100, SD: 15). ${ }^{20}$ Higher scores indicate higher IQ.

\section{Statistical analyses}

Mathematics anxiety and trait anxiety scores were skewed in both groups, therefore MannWhitney U tests were used to assess between-group differences in these outcomes. An independent samples t-test was used to test for between-group differences in mathematics attainment, and continuous outcomes in Table 1. Between-group differences in categorical outcomes (IMD deprivation classification and academic year group) were assessed using Chisquare. The relationship between mathematics anxiety and mathematics attainment was nonlinear, therefore non-parametric bivariate Spearman's rho with 95\% confidence intervals (95\% CI) and partial correlations were used to explore the relationship controlling for trait anxiety. Rho coefficients with 95\% CI for bivariate and partial Spearman's rho were computed using bootstrapping with 1000 replications in $\mathrm{R}$ (version 3.6.1) using the cor.test and spearman.ci functions (using the RVAideMemoires package ${ }^{21}$ ) and pcor.test. ${ }^{22}$ All other analyses were conducted in SPSS version 25. Cohen's d values were computed using an online calculator. ${ }^{23}$ Correlations $<0.30$ were considered weak, correlations 0.30 to 0.49 moderate and correlations $\geq 0.50$ strong. ${ }^{24}$ Numbers of participants with missing data are reported in table notes.

\section{Ethical approval}

This study was approved by the Derbyshire National Health Service Research Ethics Committee (Ref 15/EM/0284)

\section{RESULTS}

\section{Sample characteristics}


There was no significant difference in the distribution of sex between the very preterm (VP) and term-born groups. Furthermore, there were no significant differences in IMD scores, nonverbal IQ, age or academic year at assessment (Table 1).

\section{INSERT TABLE 1 HERE}

\section{Mathematics attainment}

Adolescents born VP had significantly poorer mathematics attainment than adolescents born term (-10.95 points; $95 \%$ CI -16.18 to -5.73$)$ (Table 2).

\section{INSERT TABLE 2 HERE}

\section{Mathematics anxiety}

There was no significant difference in mathematics anxiety between adolescents born VP and adolescents born at term $(\mathrm{U}=5648.0, \mathrm{p}=.417$; Table 2$)$. At item level, adolescents born VP had significantly higher scores on only two out of the 23 items (Items $11 \& 20$; See Supplementary Digital Content 1), but the differences on these items were no longer significant after Bonferroni correction. There was no significant difference in mathematics anxiety between children assessed at home or in school (School assessments: Mean 49.46 (SD 18.43); Home assessments: Mean 49.18 (SD 16.04); $\mathrm{p}=0.914)$. Thus the testing environment did not affect rates of mathematics anxiety.

\section{Trait anxiety}

Self-reported trait anxiety did not differ significantly between adolescents born VP and at term $(\mathrm{U}=5482.0, \mathrm{p}=.237$; Table 2$)$, however parents reported significantly higher trait anxiety in adolescents born VP compared to adolescents born at term $(\mathrm{U}=4402.5, \mathrm{p}=.005)$. Selfreported trait anxiety was moderately associated with mathematics anxiety in both adolescents born VP (rho .39) and at term (rho .40) (Table 3). 


\section{INSERT TABLE 3 HERE}

\section{Relationship between mathematics anxiety and mathematics attainment}

There were significant moderate associations between mathematics anxiety and mathematics attainment for adolescents born VP and for term-born controls. These associations were of an equivalent effect size and remained significant after controlling for trait anxiety in both groups (Table 3).

\section{DISCUSSION}

This is the first study to explore mathematics anxiety in adolescents born very preterm (VP). Contrary to our hypothesis, there was no significant difference in mathematics anxiety between adolescents born VP and their term-born peers. The negative correlation between mathematics anxiety and mathematics attainment in both adolescents born VP and at term remained significant once trait anxiety was controlled for. These results suggest that the relationship between mathematics anxiety and attainment evidenced in secondary school students in the general population is mirrored in the VP population. ${ }^{6}$

The lack of a significant excess of self-reported mathematics anxiety in adolescents born VP was contrary to our expectations, but it is reassuring that this was not found to be an additional risk factor for this already vulnerable population. Our results also provide reassurance that learning opportunities may not be reduced for VP adolescents due to avoidance of mathematical tasks as a result of higher levels of mathematics anxiety. ${ }^{8}$ Our results provide further evidence of a dissociation between poor mathematical performance and mathematics anxiety in groups with low mathematics attainment. ${ }^{10}$ 
Mathematics anxiety may result from the dissociation between an adolescent's performance and their own or other's expectations. Strong negative correlations are found between children's and adolescents' perceived ability and performance, and affective reactions towards mathematics, such as fear, nervousness and dread. ${ }^{25}$ Children with poorer mathematics attainment may have lower expectations of their own attainment. ${ }^{10}$ It could therefore be posited that mathematics anxiety is not evidenced when an individual's expectation of their performance is concordant with their actual performance. In addition, it may be that adolescents who attach little importance to mathematics do not experience mathematics anxiety. ${ }^{25}$

It could be speculated that adolescents born VP overestimate their mathematics performance, and therefore there is not an excessive gap between their perceived performance and actual performance compared with adolescents born at term. This may explain the lack of mathematics anxiety in adolescents born VP but requires further research. Adolescents with a specific learning difficulty, predominantly in mathematics, have been shown to overestimate their performance in mathematics compared to their actual performance ${ }^{26}$ but for adolescents born VP, their perceived performance, expectations and importance attributed to mathematics are unknown. In a previous study, preterm adolescents who had impaired executive function on neuropsychological tests compared to term-born peers did not report more difficulties than their peers on a self-report measure of executive function in daily life. ${ }^{27}$ The same pattern of findings was evidenced with trait anxiety in the present study in which there were no differences between the VP and term-born adolescents on self-reported trait anxiety, but higher parent-reported trait anxiety was observed for the VP adolescents. This pattern of findings is supported by previous literature in which parents of VLBW adolescents aged 14 years provided higher ratings of depression/anxiety compared with parents of adolescents born at term, whilst VLBW adolescents' self-reports did not differ from those of the term- 
born adolescents. ${ }^{14}$ In another study, self-reported anxiety/depression scores were lower for male adolescents with VLBW compared to normative data, ${ }^{13}$ indicating fewer symptoms than adolescents in the general population.

One hypothesis is that mathematics does not induce heightened anxiety among VP adolescents due to low importance being attributed to mathematics. As it was not possible to examine this in the present study, this is a potential avenue for future research. To test this hypothesis, motivation for and importance attributed to mathematics needs to be assessed alongside mathematics anxiety. To corroborate self-reports of mathematics anxiety, physiological assessments of anxiety when presented with mathematical stimuli could also be explored; see Ashcraft, Krause and Hopko (2007). ${ }^{28}$

Our findings suggest that interventions aimed at reducing mathematics anxiety in adolescents born VP are unlikely to improve their mathematics attainment. Alternative approaches to intervention could focus on adapting teaching to account for deficits in working memory, such as utilizing teaching strategies that reduce the student's working memory load and supporting students to develop their own strategies to optimize their learning. ${ }^{29}$ An e-learning resource for education professionals has been developed to help provide them with such strategies that can be used to support learning for preterm-born children with difficulties in working memory and other cognitive deficits associated with VP birth (see: www.pretermbirth.info). ${ }^{30}$

It should be noted that the MAS-UK was validated with an undergraduate population, and therefore its application to adolescents aged 13 years may be limited. A general challenge facing research in mathematics anxiety is the lack of a priori definition of high mathematics anxiety. Researchers have identified high mathematics anxiety as scores 1 SD above the mean, ${ }^{28}$ or scores above the 90 th percentile. ${ }^{10}$ However, without a standardized definition, it 
is difficult to identify the prevalence of mathematics anxiety in the general population ${ }^{10}$ and compare this to the VP population. It should also be noted that the measure of trait anxiety in the present study was based on three items of the SDQ. Future studies could incorporate more detailed measures of generalised anxiety. Loss to follow-up of children from the original PRISM Study cohort may also represent a limitation of the present study. As noted, $76 \%$ of the original VP children and $67 \%$ of term-born controls were re-recruited in adolescence. VP children re-assessed had similar characteristics to those that were lost to follow up, but were less likely to live in areas of high deprivation. Similarly, controls assessed in adolescence had similar characteristics to controls lost to follow up, but had higher IQ. As such we may have underestimated the adverse impact of VP birth, but such effects are likely to be minimal.

In conclusion, adolescents born VP do not have heightened mathematics anxiety compared to their term-born classmates, despite having significantly poorer mathematical attainment. Further research is needed to explore the value that VP adolescents attribute to mathematics to further understand this finding.

\section{REFERENCES}

1. MacKay DF, Smith GCS, Dobbie R et al. Gestational age at delivery and special educational need: retrospective cohort study of 407,503 schoolchildren. PLoS Med. 2010;7(6):e1000289.

2. Simms, V, Gilmore, C, Cragg, L et al. Nature and origins of mathematics difficulties in very preterm children: a different etiology than developmental dyscalculia. Pediatr Res 2015;77:389.

3. Twilhaar ES, de Kieviet JF, Aarnoudse-Moens CSH et al. Academic performance of children born preterm: a meta-analysis and meta-regression. Arch Dis Childhood-Fetal 
Neonatal Ed. 2018;103(4):F322-F330.

4. Simms V, Cragg L, Gilmore C et al. Mathematics difficulties in children born very preterm: current research and future directions. Arch Dis Child - Fetal Neonatal Ed. 2013;98(5):F457 LP-F463. doi:10.1136/archdischild-2013-303777

5. Allen K, Higgins S, Adams J. The relationship between visuospatial working memory and mathematical performance in school-aged children: a systematic review. Educ Psychol Rev. 2019:1-23.

6. Hill F, Mammarella IC, Devine A et al. Maths anxiety in primary and secondary school students: Gender differences, developmental changes and anxiety specificity. Learn Individ Differ. 2016;48:45-53.

7. Ashcraft MH. Math anxiety: Personal, educational, and cognitive consequences. Curr Dir Psychol Sci. 2002;11(5):181-185.

8. Hembree R. The nature, effects, and relief of mathematics anxiety. J Res Math Educ. 1990:33-46.

9. Ma X. A meta-analysis of the relationship between anxiety toward mathematics and achievement in mathematics. J Res Math Educ. 1999;30(5):520-540.

10. Devine A, Hill F, Carey E et al. Cognitive and emotional math problems largely dissociate: Prevalence of developmental dyscalculia and mathematics anxiety. $J$ Educ Psychol. 2018;110(3):431-444.

11. Johnson S, Hollis C, Kochhar P et al.Psychiatric disorders in extremely preterm children: longitudinal finding at age 11 years in the EPICure study. J Am Acad Child Adolesc Psychiatry. 2010;49(5):453-463.

12. Sømhovd MJ, Hansen BM, Brok J et al. Anxiety in adolescents born preterm or with 
very low birthweight: A meta-analysis of case-control studies. Dev Med Child Neurol. 2012;54(11):988-994.

13. Dahl LB, Kaaresen PI, Tunby J et al. Emotional, behavioral, social, and academic outcomes in adolescents born with very low birth weight. Pediatrics. 2006;118(2):e449-e459.

14. Indredavik MS, Vik T, Heyerdahl S et al. Psychiatric symptoms in low birth weight adolescents, assessed by screening questionnaires. Eur Child Adolesc Psychiatry. 2005;14(4):226-236.

15. Grunau RE, Whitfield MF, Fay TB. Psychosocial and academic characteristics of extremely low birth weight $(\leq 800 \mathrm{~g})$ adolescents who are free of major impairment compared with term-born control subjects. Pediatrics. 2004;114(6):e725-e732.

16. Wechsler WD. Wechsler Individual Achievement Test, 2nd Edition. London: Pearson; 2004.

17. Hunt TE, Clark-Carter D, Sheffield D. The development and part validation of a UK scale for mathematics anxiety. J Psychoeduc Assess. 2011;29(5):455-466.

18. Goodman R. Psychometric properties of the strengths and difficulties questionnaire. $J$ Am Acad Child Adolesc Psychiatry. 2001;40(11):1337-1345.

19. Department of communities and local government. The English Index of Multiple Deprivation (IMD) 2015 - Technical report.; 2015. Available at: https://assets.publishing.service.gov.uk/government/uploads/system/uploads/attachme nt_data/file/464485/English_Indices_of_Deprivation_2015_-_Technical-Report.pdf Accessed August 242020.

20. Raven J. Standard Progressive Matrices-Plus Version and Mill Hill Vocabulary Scale. 
London: Pearson; 1998.

21. Hervé M, Hervé MM. Package 'RVAideMemoire.’ 2020.

22. Kim S. ppcor: an R package for a fast calculation to semi-partial correlation coefficients. Commun Stat Appl methods. 2015;22(6):665-674.

23. Lenhard, W, Lenhard A Calculation of Effect Sizes.

doi:10.13140/RG.2.2.17823.92329

24. Cohen J. Statistical Power Analysis for the Behavioral Sciences. Routledge; 2013.

25. Wigfield A, Meece JL. Math anxiety in elementary and secondary school students. $J$ Educ Psychol. 1988;80(2):210-216.

26. Heath N, Roberts E, Toste JR. Perceptions of academic performance: Positive illusions in adolescents with and without learning disabilities. J Learn Disabil. 2013;46(5):402412.

27. Sølsnes AE, Skranes J, Brubakk A-M et al. Executive functions in very-low-birthweight young adults: a comparison between self-report and neuropsychological test results. J Int Neuropsychol Soc. 2014;20(5):506-515.

28. Ashcraft MH, Krause JA, Hopko DR. Is math anxiety a mathematical learning disability? In: Berch DB, Maocco, MM eds. Why is math so hard for some children? The nature and origins of mathematical learning difficulties and disabilities. Paul $\mathrm{H}$ Brokkes Publishing.2007:382-85.

29. Gathercole SE, Lamont E, Alloway TP. Working memory in the classroom. In: Working memory and education. The Psychologist 2006; 219-40.

30. Johnson S, Bamber D, Bountziouka V, et al. Improving developmental and educational 
support for children born preterm: evaluation of an e-learning resource for education professionals. BMJ Open. 2019;9(6):e029720. 


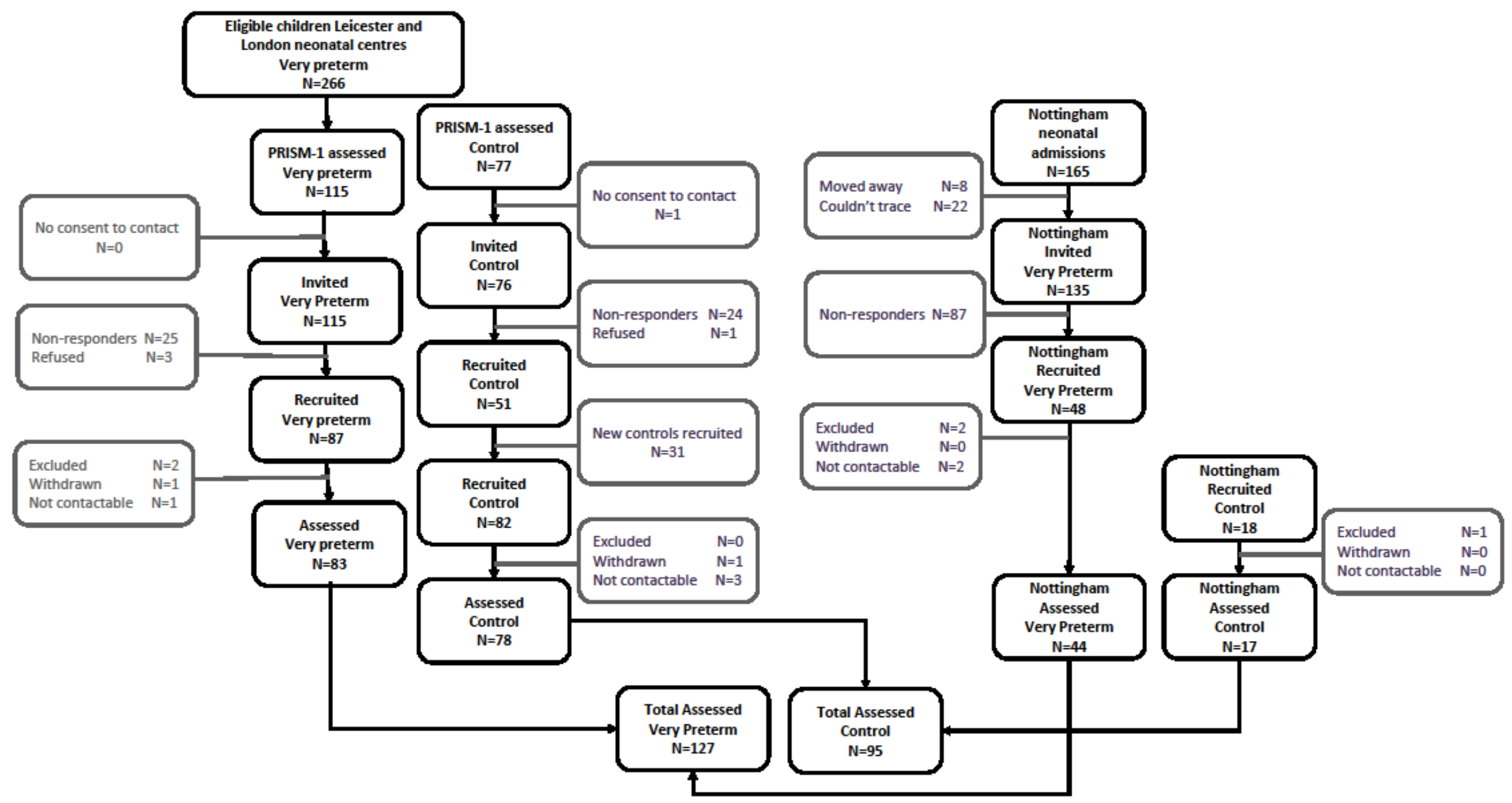

Figure 1: Flow chart of recruitment of children born very preterm and term-born controls 
Table 1

Characteristics of adolescents born very preterm ( $<32$ weeks' gestation) and at term.

\begin{tabular}{|c|c|c|c|c|}
\hline & & $\begin{array}{c}\text { Term-born } \\
\text { controls } \\
\mathbf{N}=95\end{array}$ & $\begin{array}{c}\text { Very preterm } \\
\text { adolescents } \\
\quad \mathbf{N}=127\end{array}$ & $\mathbf{p}$ \\
\hline Gestational age, weeks & Mean (SD) & - & $28.74(1.91)$ & - \\
\hline$<28^{+0}$ weeks & $\mathrm{N}(\%)$ & - & $31(24 \%)$ & - \\
\hline $28^{+0}-31^{+6}$ weeks & $\mathrm{N}(\%)$ & - & $96(76 \%)$ & - \\
\hline Birthweight, $\mathrm{g}$ & Mean (SD) & - & $1219(330)$ & - \\
\hline$<1000 \mathrm{~g}$ & $\mathrm{~N}(\%)$ & - & $39(31 \%)$ & - \\
\hline $1000-1499$ & $\mathrm{~N}(\%)$ & - & $57(45 \%)$ & - \\
\hline$\geq 1500 \mathrm{~g}$ & $\mathrm{~N}(\%)$ & - & $31(24 \%)$ & - \\
\hline Male sex & $\mathrm{N}(\%)$ & $48(51 \%)$ & $71(56 \%)$ & 0.427 \\
\hline IMD score $^{\mathrm{a}}$ & Mean (SD) & 17.66 (16.09) & $19.81(15.87)$ & 0.323 \\
\hline Low deprivation & $\mathrm{N}(\%)$ & $49(52 \%)$ & $57(45 \%)$ & 0.326 \\
\hline Mid deprivation & $\mathrm{N}(\%)$ & $26(27 \%)$ & $32(25 \%)$ & \\
\hline High deprivation & $\mathrm{N}(\%)$ & $20(21 \%)$ & $38(30 \%)$ & \\
\hline White ethnicity ${ }^{b}$ & $\mathrm{~N}(\%)$ & $73(77 \%)$ & $96(76 \%)$ & 0.868 \\
\hline Age at assessment, years & Mean (SD) & $13.70(0.74)$ & $13.87(0.68)$ & 0.076 \\
\hline & Median (IQR) & $\begin{array}{c}13.72 \\
(13.21-14.28)\end{array}$ & $\begin{array}{c}14.04 \\
(13.33-14.45)\end{array}$ & 0.089 \\
\hline Academic year & & - & - & 0.525 \\
\hline Year 7 & $\mathrm{~N}(\%)$ & $6(6 \%)$ & $4(3 \%)$ & \\
\hline Year 8 & $\mathrm{~N}(\%)$ & $34(36 \%)$ & $41(32 \%)$ & \\
\hline Year 9 & $\mathrm{~N}(\%)$ & $43(45 \%)$ & $60(48 \%)$ & \\
\hline Year 10 & $\mathrm{~N}(\%)$ & $12(13 \%)$ & $22(17 \%)$ & \\
\hline Non-verbal IQ & Mean (SD) & $98.26(18.10)$ & $94.13(17.84)$ & 0.091 \\
\hline
\end{tabular}


Table 2

Between-group comparisons of mathematics attainment, mathematics anxiety and trait anxiety

\begin{tabular}{cccccc}
\hline & & $\begin{array}{c}\text { Term-born } \\
\text { controls } \\
\mathbf{n = 9 5}\end{array}$ & $\begin{array}{c}\text { Very preterm } \\
\text { adolescents } \\
\mathbf{n = 1 2 7}\end{array}$ & p & $\begin{array}{c}\text { Cohen's } \\
\text { d }\end{array}$ \\
\hline $\begin{array}{c}\text { Mathematics attainment: } \\
\text { WIAT-II Composite Score }\end{array}$ & Mean (SD) & $107.46(17.10)$ & $96.51(21.19)$ & $<.001$ & -0.57 \\
$\begin{array}{c}\text { Numerical operations: } \\
\text { WIAT-II Sub-scale score }\end{array}$ & Mean (SD) & $109.65(18.51)$ & $99.07(22.57)$ & $<.001$ & -0.51 \\
$\begin{array}{c}\text { Mathematics Reasoning: } \\
\text { WIAT-II Sub-scale score }\end{array}$ & Mean (SD) & $103.24(15.57)$ & $94.59(15.74)$ & $<.001$ & -0.55 \\
Mathematics anxiety & Median (IQR) & $47.0(34.0-57.0)$ & $45.0(36.0-63.0)$ & .417 & 0.11 \\
Trait anxiety: Self report & Median (IQR) & $2.0(1.0-3.0)$ & $2.0(1.0-3.0)$ & .237 & 0.16 \\
Trait anxiety: Parent report & Median (IQR) & $1.0(0-2.0)^{\mathrm{a}}$ & $1.0(0-3.0){ }^{\mathrm{b}}$ & .005 & 0.37 \\
& & & & & \\
\hline
\end{tabular}

${ }^{a}$ Due to unreturned questionnaires Control $n=91$

${ }^{\mathrm{b}}$ Due to unreturned questionnaires VP $\mathrm{n}=12$ 
Table 3

Spearman rho bivariate and partial correlations between mathematics anxiety and mathematics attainment in very preterm (VP adolescents) and term-born controls.

\begin{tabular}{llcccccc}
\hline & & $\begin{array}{c}\text { Mathematics } \\
\text { attainment }\end{array}$ & $\begin{array}{c}\text { Self-reported } \\
\text { trait anxiety }\end{array}$ & $\begin{array}{c}\text { Mathematics attainment } \\
\text { controlling for trait } \\
\text { anxiety }\end{array}$ \\
\hline & Rho & $95 \% \mathrm{CI}$ & Rho & $95 \% \mathrm{CI}$ & Rho & $95 \% \mathrm{CI}$ \\
\hline $\begin{array}{l}\text { Mathematics } \\
\text { anxiety }\end{array}$ & Controls $(\mathrm{N}=95)$ & $-.50^{* *}$ & $-.65 ;-.34$ & $.40^{* *}$ & $.20 ; .58$ & $-.54 * *$ & $-.66 ;-.38$ \\
& $\mathrm{VP}(\mathrm{N}=127)$ & $-.50^{* *}$ & $-.62 ;-.37$ & $.39 * *$ & $.24 ; .53$ & $-.45^{* *}$ & $-.58 ;-.30$ \\
\hline
\end{tabular}

$* * \mathrm{p}<.001$ 
Table S1: Mean (SD) scores on of individual items in Mathematics Anxiety Scale UK

\begin{tabular}{|c|c|c|c|}
\hline & $\begin{array}{l}\text { Term-born controls } \\
\qquad \mathrm{n}=95\end{array}$ & Very Preterm n=127 & $\begin{array}{c}\text { Between group } \\
\text { comparison }\end{array}$ \\
\hline & Mean (SD) & Mean (SD) & $\mathrm{P}$ value \\
\hline Item 1 (Having someone watch you multiply $12 \times 23$ on paper) & $2.35(1.24)$ & $2.40(1.32)$ & .757 \\
\hline Item 2 (Adding up a pile of change) & $1.88(0.12)$ & $1.91(1.21)$ & .888 \\
\hline Item 3 (Being asked to write an answer on board in front of class) & $2.57(0.13)$ & $2.50(1.20)$ & .700 \\
\hline Item 4 (Being asked to add up number of people in a room) & $1.73(1.05)$ & $1.79(1.18)$ & .661 \\
\hline Item 5 (Calculating how many days until a person's birthday) & $2.02(1.06)$ & $2.09(1.16)$ & .629 \\
\hline
\end{tabular}


Item 6 (Taking a maths exam)

Item 7 (Being asked to calculate $£ 9.36 / 4$ in front of people)

Item 8 (Being given a telephone number and remembering it)

Item 9 (Reading the word algebra)

Item 10 (Calculating a series of multiplication problems on paper)

Item 11 (Working out how much time left before school)

Item 12 (Listening to someone talk about maths)

Item 13 (Work out change in a shop) 
Item 14 (Splitting the cost of an object)

Item 15 (Reading a maths textbook)

Item 16 (Watching someone do algebra)

Item 17 (Sitting in a maths class)

Item 18 (Being given a surprise maths test in a class)

Item 19 (Being asked to memorise a multiplication table)

Item 20 (Watching a teacher write equations on the board)

Item 21 (Being asked to calculate $3 / 5$ as a percentage) 
Item 22 (Working out how much a shopping bill comes to)

Item 23 (Being asked a maths question by teacher in front of class)
$2.54(1.19)$

$2.54(1.31)$

$*_{\mathrm{p}}<.05$, not significant after Bonferroni correction for multiple comparisons $(\mathrm{p}<.002)$ 